\title{
Transatlantica
}

Revue d'études américaines. American Studies Journal

\section{Des guides touristiques pour le peuple et par le peuple}

Le Federal Writers' Project et l'invention d'une culture folklorique américaine (1935-1941)

\section{Ninon Vinsonneau}

\section{(2) OpenEdition}

Journals

Édition électronique

URL : http://journals.openedition.org/transatlantica/246

DOI : $10.4000 /$ transatlantica.246

ISSN : $1765-2766$

Éditeur

AFEA

Référence électronique

Ninon Vinsonneau, «Des guides touristiques pour le peuple et par le peuple », Transatlantica [En ligne] 1 | 2006, mis en ligne le 05 avril 2006, consulté le 29 avril 2021. URL : http://journals.openedition.org/ transatlantica/246 ; DOI : https://doi.org/10.4000/transatlantica.246

Ce document a été généré automatiquement le 29 avril 2021.

\section{(c) () $\odot$ EY NC ND}

Transatlantica - Revue d'études américaines est mis à disposition selon les termes de la licence Creative Commons Attribution - Pas d'Utilisation Commerciale - Pas de Modification 4.0 International. 


\title{
Des guides touristiques pour le peuple et par le peuple
}

\author{
Le Federal Writers' Project et l'invention d'une culture folklorique
} américaine (1935-1941)

\section{Ninon Vinsonneau}

1 Le Federal Writers' Project (FWP) constitua l'un des quatre programmes « culturels » lancés par l'administration du New Deal en 1935 en vue de résorber le problème du chômage parmi les professions dites «en col blanc». Il employa de 1935 à 1943, entre quatre et six mille chômeurs par an, tous membres des «professions de l'écrit »- les "écrivains", au sens large que l'administration fédérale donnait à ce terme: romanciers, poètes, dramaturges, mais aussi journalistes, enseignants, chercheurs et autres «membres des professions libérales", dont les liens avec l'écriture étaient des plus ténus. Ces « écrivains fédéraux » furent à l'origine des 378 publications (collectives et anonymes) du FWP, dont l'American Guide Series, collection de quarante-huit guides touristiques sur chacun des états des Etats-Unis et fleuron de la production. Les autres publications - guides de villes, de sites touristiques, de routes et voies fluviales, " portraits » de communautés régionales, ethniques et/ou professionnelles - furent en effet des à-côtés du projet initial, nés de la masse considérable de "données " accumulées au fil des recherches entreprises pour les guides d'état et restées inutilisées.

2 Lors de la "Semaine du guide américain », proclamée par Roosevelt en honneur de la sortie du dernier volume de la collection en novembre 1941 (quelques semaines avant Pearl Harbor), la direction du FWP mit l'accent sur le caractère "populaire » des guides, et la plupart des critiques de l'époque s'accordèrent à saluer une oeuvre "pour le peuple et par le peuple». Produite par des «hommes du peuple»-chômeurs certifiés "sans ressources" par les services sociau - la collection prétendait aussi s'adresser aux «hommes du peuple »-c'est-à-dire d'abord, à tout le monde: aussi bien visiteurs étrangers à la région que promeneurs du week-end résidant dans l'état, touristes que " voyageurs en chambre ", chercheurs érudits que simples curieux. Mais le «peuple» du discours promotionnel désignait aussi bien sûr «la masse » par 
opposition à l'élite, la majorité plutôt que les « happy few » de la classe des loisirs. Cette classe des loisirs s'était au demeurant considérablement élargie depuis le début du siècle et l'avènement des « loisirs de masse » qui avait radicalement changé la donne touristique. Les guides du FWP, contrairement à leurs équivalents européens de la fin $\mathrm{du}$ dix-neuvième siècle (guides Baedekers, Bleus, Cook) n'enseignaient plus seulement les rudiments d'une culture bourgeoise, éternelle et immuable. Ils célèbraient avant tout l'« Amérique d'en bas ", faite de " petites gens » anonymes, de minorités ethniques et de communautés ouvrières. Dès le début des opérations en 1935, la direction avait recommandé à ses employés d'envisager leur rôle comme celui de "messagers de bonne volonté », et leur entreprise comme « le travail le plus précieux jamais entrepris pour le compte de la culture et de la communauté américaines» (American Guide Manual). Il s'agissait à la fois d'être plus «honnêtes » que les brochures publicitaires qui avaient jusque- là tenu lieu de littérature touristique, et plus « démocratiques » que les guides Baedekers et autres collections européennes, souvent citées en contre exemple. Il fallait parler de tous et à tous, et non se limiter au «meilleur » de ce que le pays avait à offrir.

3 L'historiographie consacrée aux guides du FWP tourne essentiellement autour de la question de savoir à qui ces "guides pour tous " s'adressaient véritablement. Dans un ouvrage récent (1999), Christine Bold apporte un correctif salutaire aux conclusions enthousiastes des historiens des années 1960 et 1970 (McDonald, Mangione, Penkower) qui avaient un peu hâtivement célébré le caractère novateur et radical de l'entreprise new dealienne. A l'inverse, Bold met en évidence le caractère éminemment construit de la «perspective populaire " que les guides étaient censés incarner et souligne le contrôle exercé par la direction du projet - dont aucun des membres n'était au chômage ou sans ressource - sur l'ensemble de la production. Loin de constituer des guides "pour le peuple et par le peuple», Bold conclue qu'ils expriment avant tout le point de vue d'une direction formée en majorité de libéraux blancs de la côte Est.

4 Le processus de production des guides, mis en place par la direction, lui réservait en effet un droit de veto sur les manuscrits qui restreignait considérablement la liberté des auteurs. Ceux-ci - entre 4500 et 5200 employés selon les années et le budget alloué par le Congrès - étaient répartis en quarante neuf équipes - une par état plus une pour la seule ville de New York, richement dotée en écrivains au chômage - et devaient procéder dans un premier temps à l'élaboration d'un " manuscrit de terrain ", première mouture « de quarante à cinquante fois plus longue » que le manuscrit publié. Cette version devait ensuite être «condensée» par une équipe réduite de " rédacteurs » au sein de chacune des équipes - un à dix employés "qualifiés » par équipe, selon le nombre total d'employés, lui-même indexé sur la densité de population de l'état. Le «manuscrit local » mis au point par ces rédacteurs était enfin envoyé à la direction à Washington pour relecture et corrections. Ces corrections n'étaient pas directement portées par les membres de la direction, qui se contentaient de remarques et recommandations en marge du manuscrit ensuite renvoyé à l'équipe locale pour qu'elle effectue elle-même les modifications et ajustements nécessaires. Les manuscrits effectuaient ainsi parfois plusieurs allers-retours entre l'échelon local et l'échelon fédéral - ces «recommandations » faisant naturellement l'objet de contestations et négociations multiples - avant d'obtenir l'aval de la direction pour publication.

5 La direction fédérale - une soixantaine de membres dont un "noyau dur " d'une dizaine de dirigeants - contrôlait également la production en amont. La table des 
matières, commune à l'ensemble des volumes de la collection et préétablie par le "noyau dur" des dirigeants, comme les questions de style, qui firent l'objet de nombreux «manuels d'instructions " à l'attention des rédacteurs locaux, donnèrent à l'ensemble des guides une grande uniformité de facture (uniformité quelque peu paradoxale pour des guides qui entendaient justement célébrer la diversité régionale d'une Amérique morcelée en mosaïque d'états à l'identité distincte). Tous les guides de la collection se divisent ainsi en trois partie : la première moitié de chaque volume est consacrée aux essais thématiques, qui forment une sorte de longue introduction, et dont les "entrées" avaient également été choisies par la direction. Aux thèmes "classiques »-géographie, histoire, industrie, commerce, agriculture, arts, folklore-venaient s'ajouter quelques nouveautés-comme les «minorités ethniques», les «Noirs» et le «monde du travail» («labor») - qui signifiaient la volonté de la direction de mettre le « peuple » au centre des guides. La deuxième moitié des guides est consacrée aux itinéraires, qui obéissent à un quadrillage strict du territoire (d'Est en Ouest et du Nord au Sud), également imposé par la direction fédérale. Enfin, entre ces deux grosses parties qui forment l'essentiel de chaque volume venait s'intercaler une partie nettement plus succincte consacrée aux villes, classées par ordre alphabétique.

6 Une grande unité de style caractérise l'ensemble de la collection. En rupture avec la rhétorique flamboyante des dépliants publicitaires, le style des guides du FWP se voulait sobre, factuel, précis, volontiers "plat», ou, pour reprendre le terme fréquemment employé par la direction, « honnête ». Une honnêteté qui ne fut pas pour autant synonyme de spontanéité, puisque la simplicité du style requit de nombreux efforts et ajustements. "Le style doit être un modèle de précision succincte", recommandait le premier manuel d'instructions d'octobre 1935. La direction se livra à une véritable chasse aux superlatifs et expressions toutes faites: « [les formules du type] «le meilleur», "le plus important» ou «le plus beau» sont à manier avec précaution. L'emphase ou l'exagération sont à éviter dans les descriptions comme les commentaires ", recommandait le manuel d'instructions. "Serait-ce trop choquer la délicate sensibilité sudiste que de parler de "traite des vaches", plutôt que d'une "activité typique de la frontière»?", s'interrogeait un correcteur fédéral du manuscrit du Kentucky. Souvent sommée de choisir entre le fleuri et le plat, la direction préféra généralement le plat: « l'essai sur Covington est sec et factuel, mais ces caractéristiques correspondent peut-être à l'ambiance de Covington ", précise ainsi le correcteur. Ces nombreux rappels à l'ordre stylistique et au devoir d'objectivité se soldèrent souvent au final par une surabondance de données chiffrées, livrées sans commentaire. L'essai consacré aux "minorités ethniques» se réduit par exemple souvent à une collection de statistiques directement issues du bureau du Recensement. Et les «itinéraires» regorgent de mesures en tous genres, de distances, de hauteur (pour les montagnes), d'âge (d'une ville depuis sa fondation), de densité de populations, etc.

7 La grande uniformité de ton et de facture des divers volumes de la collection témoignent du travail d'homogénéisation opéré par le bureau central sur les production locales. Mais cette unité formelle de l'ensemble masque une grande variété de contenus qui mettent l'historien au défi de généraliser. En effet, si les équipes locales du FWP se plièrent presque toutes aux contraintes formelles imposées par la direction, elles n'en respectèrent pas toujours l'esprit, loin s'en faut. Aussi centralisée soit-elle, la production des guides accordait en effet aux rédacteurs un certain pouvoir : celui par 
exemple, de ne pas reporter les corrections recommandées. La distance et le volume de la production nuirent à l'efficacité de la direction, qui fut dans l'obligation de déléguer une partie de ses pouvoirs. Les équipes locales se jouèrent par ailleurs des ambitions de la direction à faire oeuvre populaire, et des réticences de nombre de ses membres à « imposer» leurs vues aux équipes locales. «La question se pose de savoir qui, de vous ou de moi, se fait une idée correcte de ce que vous voulez accomplir», lance ainsi fièrement Vardis Fisher, directeur de l'Idaho.

Comme l'ont montré bon nombre d'études (Corbin, Thiesse), les séries de guides européens qui se multiplièrent au dix-neuvième siècle tendaient à produire une image consensuelle et rassurante de la nation dont étaient notamment absentes les «classes laborieuses, classes dangereuses». Produits sous l'égide d'une direction fédérale acquise au progrès social de la classe ouvrière et composée de nombreux "radicaux " de la gauche libérale, les guides du FWP n'adoptent pas dans leur ensemble un discours aussi conservateur que celui des collections européennes. Il ne s'agissait pour eux ni de réaffirmer un quelconque status quo ante, ni de nier l'existence ou l'importance des «masses populaires ». Le découpage de l'histoire que reprennent la plupart des guides s'inspire ainsi d'une interprétation progressiste et célèbre au contraire la lente et sûre conquête de la démocratie par les masses. Loin de faire de la révolution le pivot de l'avènement démocratique, ce récit en faisait plutôt le fondement théorique, dont l'aboutissement pratique - la démocratie de masse - avait mené à une lutte acharnée du peuple démocratique contre les élites ploutocrates tout au long dix-neuvième siècle. Cette lecture de l'histoire, calquée sur l'ouvrage en vogue des historiens Charles et Mary Beard, The Rise of American Civilization - dont la direction recommandait d'ailleurs la lecture aux employés - faisait du New Deal, plus que de la révolution de 1776, le véritable moment de l'avénement démocratique. Ce récit permettait en outre au passage de faire du New Deal l'héritier naturel d'une longue tradition démocratique, et d'en gommer le caractère foncièrement novateur. S'il n'était pas fondamentalement nouveau, ce récit de l'histoire ne se distinguait pas moins nettement du portrait conservateur de la " nation éternelle » caractéristique des guides européens.

Mais plus encore que l'histoire, c'est la culture qui constitue le domaine par excellence des guides touristiques. Et si dans les guides du FWP, la « démocratie de masse » est au cœur du récit historique, la culture de masse n'y est pas célébrée avec autant de ferveur. Bold fait même de son absence ou de son effacement du paysage américain la caractéristique principale du travail des guides.

10 Le format «morcelé » de la collection postulait en effet par avance une certaine diversité culturelle qui contredisait le travail d'homogénéisation des formes et pratiques culturelles à l'échelle nationale opéré par l'essor de la "culture de masse » depuis le début du siècle. Ce "régionalisme par décret» (selon l'expression de Karal Ann Marling, citée dans Bold, 30) mobilisa tous les efforts de la direction : les premiers manuscrits qui lui parvinrent du « terrain » ne correspondaient en rien à ses attentes et témoignaient au contraire de la «standardisation » avancée du paysage et de la nation. «Le terminus des bus ne constitue pas un site digne d'intérêt dans la mesure où on en trouve dans au moins 100 autres villes américaines ", souligne ainsi un correcteur fédéral en marge du manuscrit du Kentucky. L'ensemble des «sites»-les fameux «points of interest»-choisis par les auteurs du guide sont d'ailleurs jugé "plutôt communs» et inappropriés: "n'y a-t-il donc aucun lieu présentant un intérêt architectural, ou esthétique [à Ashland] ? » s'indigne le relecteur en conclusion. Comme 
le formula Katherine Kellock, justement en charge des «itinéraires » au sein de la direction : «la nécessité de trouver quelque chose à dire sur chaque communauté et la campagne alentour obligea [les auteurs] à examiner de plus près villes et campagnes, et à déterminer ce qui faisait que chaque communauté était différente des autres" (Kellock, 474).

11 Les guides recensent donc abondamment le "pittoresque», le "désuet», le «folklorique »: l'accent «élizabéthain» des Ecossais des Appalaches, les musiques noires du vieux Sud, les pratiques ancestrales des Indiens des réserves, que la loi dite de " réorganisation » tribale de 1934 allait aider, eux au moins, à résister aux assauts de la "civilisation moderne". L'Amérique des guides est avant tout une Amérique de folklores, comme en attestent les nombreuses variantes du concept qui y circulent - «folk lore ", «folk customs ", «folk culture ", " oral lore », « folk ways " mais aussi « Negro lore ", "Indian lore », etc. Le folklore déborde largement le cadre paysan ou indien auquel il était jusque-là confiné comme le cadre étroit du chapitre explicitement consacré au "folklore». Tous les états, y compris les états les plus industrialisés (du Nord Est des Etats-Unis) et toutes les communautés, y compris urbaines et ouvrières, sont douées de folklore. Et la plupart des domaines abordés par les guides sont envisagés sous l'angle folklorique : il y a donc par exemple un «folklore industriel ", fait de jargons, de pratiques sociales, de légendes urbaines et de plaisanteries de corps de métier, au même titre qu'il y a un folklore indien, un folklore noir ou un folklore paysan.

En cela, les guides du FWP appartiennent à leur temps. Les années 1930 furent en effet une grande décennie pour le folklore, et plus généralement pour la «culture ", au sens anthropologique du terme, souvent synonyme de "folklore». Lorsque l'historien Warren Susman parle de "découverte du concept de culture»-dont il fait la «caractéristique principale » des années 1930 - il ne s'agit en effet de rien d'autre que de cet élargissement du champ folklorique à des populations et des régions qui en étaient jusque-là exclues. Tel M. Jourdain, qui faisait de la prose sans le savoir, l'Amérique des années 1930 se découvrait soudain riche de cultures insoupçonnées. Et ces cultures, qu'elle baptisa "folklores ", tombaient pour les guides à point nommé : car si l'Amérique n'était pas riche en Culture (au sens "arnoldien» et noble du terme) - et à laquelle la littérature touristique s'était souvent limitée - elle se trouvait en revanche dotée de richesses folkloriques incomparables.

13 L'« Amérique, terre de folklore " relevait pourtant du paradoxe: depuis la fin du dix-neuvième siècle, les folkloristes s'étaient en effet appliqués à l'en déposséder. Le folklore, c'était précisément ce dont étaient dépourvus les Américains, c'était tout ce qui échappait - et s'opposait - à leur "civilisation» moderne et industrielle. Il subsistait bien encore quelques enclaves folkloriques en Amérique, mais ces communautés anachroniques étaient voués à disparaître ou à ne subsister qu'en marge de la société, "étrangères" à la nation: coupées du monde, au fond des vallées encaissées des Appalaches subsistaient encore quelques Ecossais dont les "ballades » avaient tant fasciné les premiers folkloristes. Les Pueblos perdus au fond du désert du Nouveau Mexique et d'Arizona perpétuaient encore leurs traditions. Et dans les champs de coton du vieux Sud restaient encore quelques chanteurs de blues et de Negro Spirituals. Mais ces communautés inassimilées et inassimilables, qui avaient tant séduit folkloristes et anthropologues au tournant du siècle, menaçaient maintenant de 
s'éteindre, contraignant les anthropologues à rejoindre le Mexique et laissant les folkloristes orphelins.

14 Mais à partir des années 1920 un vent de révolte souffle au sein de la communauté des folkloristes, pour finir dans les années 1930 à la remise en question de cette définition « historique» de la discipline. Ces jeunes folkloristes, regroupés autour de la revue Folk-Say et de son fondateur et collaborateur régulier Benjamin Botkin, rejètent l'idée selon laquelle seules les communautés «isolées" seraient douées de folklore et postulent à l'inverse que toute communauté humaine quelle qu'elle soit $-\mathrm{y}$ compris moderne et industrielle - est nécessairement " productrice » de folklore et peut à ce titre intéresser le folkloriste. Cette nouvelle conception redéfinissait radicalement le champ théorique et pratique de la discipline. Le concept de «folklore vivant » (living lore), qui résumait cette entreprise de redéfinition - et dont s'emparèrent les guides - ouvrait en effet le domaine des recherches folkloriques à tous les Américains, aussi « modernes » et " civilisés » soient-ils. Comme le formulait l'écrivain Zora Neale Hurston, ancienne élève de Franz Boas qui se définissait elle-même comme folkloriste et qui fut un temps membre de l'équipe du FWP en Floride: " aucune contrée n'est primitive au point de ne pas avoir de folklore, ni aucun pays aussi civilisé au point de ne plus en produire". Ces folkloristes "nouvelle manière" laissaient d'ailleurs volontiers aux anthropologues le soin d'examiner les derniers vestiges des cultures indiennes pour leur préférer les communautés urbaines d'ouvriers de l'industrie dont les rituels, les traditions, les légendes et les superstitions attendaient encore d'être passés au crible de l'analyse folklorique.

15 Cette redéfinition du domaine folklorique présentait de nombreux avantages pour l'entreprise du FWP : plus démocratique que la conception «historique», elle dotait libéralement tous les états de nombreuses richesses culturelles insoupçonnées. Et plus « inclusive », elle entrait en résonance avec l'entreprise de construction d'une identité culturelle nationale multiculturelle au coeur de l'entreprise des guides. La direction s'empara donc rapidement de cette définition, comme en atteste un des premiers manuels d'instructions à l'attention des équipes locales daté du début de l'année 1936 : « il existe deux types de folk-lore (sic) : le premier s'attache à ce qui peut être relié à un passé dont on a la nostalgie...le deuxième...postule que l'activité créatrice fonctionne toujours. Il reconnaît les origines européennes de la culture américaine mais s'intéresse aux mutations et développements opérés depuis le transfert sur une terre nouvelle et pionnière ». Sans rejeter explicitement la première définition du folklore, le manuel de la direction encourageait les employés à ne pas en négliger la deuxième.

16 L'attrait de cette définition nouvelle était en effet avant tout d'ordre pratique : il s'agissait en effet moins de choisir entre ces deux conceptions concurrentes que de les utiliser l'une et l'autre selon les besoins des guides et les états considérés. Les communautés folkloriques «traditionnelles » constituaient de précieuses ressources culturelles dont les guides n'entendaient nullement se passer. Mais s'ils documentent largement un imaginaire folklorique dont l'assise réelle était évanescente, ils juxtaposent à ces communautés "pittoresques" à fonction essentiellement "décorative ", d'autres "cultures folkloriques» dont l'assise imaginaire était, elle, nettement moins établie - mineurs et ouvriers de l'industrie et «new Negroes» notamment.

En juillet 1936, un an après le lancement des opérations, la direction du FWP se dota d'un «consultant en folklore» en la personne de John Lomax, folkloriste texan 
spécialiste des musiques de cow-boys. La personnalité et la carrière de Lomax résument à elles seules les ambiguïtés et contradictions de l'entreprise du FWP. Né en 1867 dans le Mississippi, John Lomax appartenait par bien des côtés à la «vieille garde » des folkloristes "nostalgiques». Le folklore relevait à ses yeux moins du domaine du "vivant» que de celui du "survivant", et comme les folkloristes de la première génération, son travail s'était accompli sous le signe de l'urgence, urgence à recueillir un précieux legs culturel auprès de populations en voie de disparition. Mais contrairement aux folkloristes de la première génération, Lomax ne s'intéressa ni au folklore indien ni au folklore européen. Il fut au contraire un des premiers à s'intéresser à une forme de folklore américain : la musique des petits blancs du Sud, et notamment les chansons de cow-boys. Choix atypique, qui fut en partie à l'origine d'un relatif manque de reconnaissance institutionnelle. Avant les années 1930, la carrière de Lomax connaît plusieurs revers qui le conduisent finalement à abandonner la recherche et à quitter le Texas, son terrain de recherche, pour aller s'établir en Illinois, où il devient banquier. Mais à partir des années 1930, ses projets trouvent un écho nettement plus enthousiaste auprès d'institutions prestigieuses. En 1931, la Bibliothèque du Congrès le charge de procéder à l'enregistrement de musiques folkloriques à travers tous les états du Sud et lui prête pour ce faire son volumineux matériel d'enregistrement. Cette collaboration avec la Bibliothèque du Congrès, qui se prolongea finalement sur dix ans, fut à l'origine d'un exceptionnel fonds d'archives sonores de plus de dix mille chansons - musiques blanches (country) mais aussi noires (blues, Negro spirituals et chansons d'esclaves)-pour lequel Lomax est resté justement célèbre. Lomax le "puriste » fut donc paradoxalement un des grands passeurs et diffuseurs d'une culture et d'une musique noires dont il déplorait la " corruption " inéluctable du fait justement de sa diffusion. Car Lomax opposait à ces formes musicales folkloriques «pures " (blues, Negro spirituals et chansons d'esclaves) une autre musique noire, commerciale et « corrompue » celle-là : le jazz. L'attachement de Lomax aux formes "pures» de la culture noire était indissociable d'une certaine nostalgie des conditions qui avaient rendu possible cette culture, à savoir l'esclavage, ou tout du moins la ségrégation raciale, condition sine qua non du développement, de la préservation et de la perpétuation de cette culture « authentique ».

Loin d'être réservées à Lomax, ces contradictions et ambiguïtés caractérisaient bien au contraire l'ensemble de la discipline folklorique-voire anthropologique. C'est d'ailleurs précisément en réponse à cette impasse politique à laquelle conduisait l'anti-modernisme nostalgique des folkloristes qu'emergea le concept de «folklore vivant ». En rejetant explicitement la notion d'authenticité en folklore, ce nouveau folklore entendait également libérer les Noirs de leur "prison folklorique ». Comme le soulignait Botkin en 1929 : «le mouvement folklorique doit remonter du bas plutôt que venir d'en haut. Il risque sinon de se réduire à un geste méprisant, un désir nostalgique, une plainte élégiaque, une tentative avortée de revival - un geste d'aristocrates paternalistes fascinés par les bas-fonds, de dilettantes provinciaux fascinés par les autochtones, ou de sentimentaux déçus de retour à la terre, et finalement de n'importe qui et tous ceux qui se sentent une âme de collectionneur ».

19 Loin d'être le signe d'un engagement politique "progressiste ", l'exaltation de la culture et du folklore noir dans les guides signale bien souvent à l'inverse les limites certaines de leur militantisme. Les guides du Kentucky, de Caroline du Nord et de Caroline du Sud sont caractéristiques de ces contraditctions : juxtaposant descriptions sommaires des discriminations raciales et récits des "contributions" de la 
communauté noire à l'état (notamment culturelles, notamment musicales), ces guides font de la ségrégation une solution de compromis acceptable aux violences provoquées par l'abolition de l'esclavage et aux abus de la Reconstruction. Le guide de Caroline du Nord souligne que «la ségrégation dans les écoles a fourni aux Noirs des opportunités dont ils n'auraient pas pu bénéficier autrement", et que la ségrégation dans les hôpitaux « donne aux directeurs et docteurs noirs l'occasion de pratiquer leur métier » et «aide à la formation d'infirmières noires ». Perspective que l'on retrouve dans le guide de Caroline du Sud, même s'il concède néanmoins que pendant la Reconstruction, " un certain nombre de Noirs instruits gardèrent la tête froide » et que c'est sous une « assemblée législative composée en majorité de Noirs » que fut introduit « un projet de loi qui conduisit à l'établissement d'un système éducatif public ».

Cette perspective "consensuelle» est à mettre en regard avec la perspective virulemment raciste des guides du Mississippi et de l'Alabama d'un côté, et avec le discours ouvertement militant des guides de Géorgie et de Virginie de l'autre. Ces derniers rejètent explicitement la notion de folklore noir ou même d'identité culturelle noire, et tentent d'esquisser les contours d'un «nouveau folklore noir ", débarrassé de ses scories racistes. Le guide de Virginie parle d'un "nouveau folklore» musical, mélange de "compositions de la ville et de Negro spirituals", tandis que le guide de Géorgie parle du "métissage généralisé » qui «a produit ce qu'on peut considérer comme une race nouvelle - afro-américaine - qui n'a que peu ou rien à voir avec ses origines africaines ». Ces deux guides se distinguent également par leur dénonciation sans ambages des discriminations raciales. Le guide de Géorgie dénonce avec virulence la ségrégation : loin d'allier séparation et égalité, « les écoles noires sont en général mauvaises, sous-équipées, en manque de personnel, et jusqu'à récemment aucun effort n'avait été fait pour créer des lycées». Le guide de Virginie, qui se présente comme " autant une confession qu'un éloge, plus centré sur les besoins présents que sur les gloires passées" se livre de fait à une critique détaillée des discriminations raciales au centre aussi bien du chapitre consacré aux Noirs que du chapitre " histoire». Aux descriptions convenues de paysans noirs du vieux Sud, le guide de Virginie préfère une scène quotidienne de la vie dans les quartiers noirs où la "fierté » raciale s'incarne dans un «bavardage » incessant: «pour les non-initiés, la foule [des quartiers noirs] n'est composée que d'oisifs qui noient leur ennui dans un bavardage sans queue ni tête. Ce bavardage représente pourtant la seule forme de distraction pour le Noir à la fin d'une journée de travail dans le monde de l'homme blanc. Aussi insouciants qu'ils semblent en apparence, ces hommes portent en eux la marque de la pauvreté, de la maladie, et de la souffrance - marques de naissance d'un peuple qui vit dans la précarité mais d'un peuple virginien à part entière ».

21 Un ton militant aux antipodes de celui adopté par le guide du Mississippi qui livre lui aussi une description de l'ambiance dans un quartier noir : “'Saddy' ('Sam'di' ndlr) est le jour du Noir. Ce jour-là, il est pressé, et ceux qui n'appartiennent pas à sa race seront probablement ignorés, bousculés, écrasés, ou coincés au milieu de la foule pendant des heures. Le Noir n'agit pas ainsi intentionnellement, mais le samedi, les blancs sont tout simplement devenus invisibles à ses yeux, sauf ceux qui lui doivent quelque chose » (chapitre « Negro Folkways»). Comme les guides de Virginie et de Géorgie, mais pour des raisons opposées, le guide du Mississippi rechigne à parler de " culture noire » ou de "folklore noir ». Cette " culture " se résume ici à une « musique africaine bizarre " et à des cérémonies vaudoues ou le prédicateur 'geint, grogne et exprime quantité d'émotions psychologiques qu'il ne comprend pas lui-même». Seuls les blancs du 
Mississippi sont doués d'un véritable "folklore »-fait de barbecues à la sortie de la messe et de meetings électoraux - décrit avec une précision d'anthropologue et une admiration explicite pour l'endurance de ce petit peuple de fermiers, «colonne vertébrale de l'état, non pas parce que nous sommes doués de vertus particulières mais parce que nous sommes une majorité et nous avons le droit de vote ». La valeur de cette culture blanche tient aussi à son triomphe ultime non seulement sur les Noirs mais aussi sur les riches propriétaires terriens qui, déplorent les auteurs, ont trop souvent occupé l'imaginaire des écrivains comme des voyageurs. Le guide entend donc rendre à cette «culture folklorique » à part entière la place qui lui revient et célébrer ces «faibles » qui ont fini par « hériter de la terre ».

L'exaltation du folklore noir dans ses formes «traditionnelles »- de musiques noires, Negro spirituals et blues en tête-correspond donc à une stratégie narrative " médiane » : ni ouvertement raciste, comme celle du guide du Mississippi, qui nie à la communauté noire tout statut « culturel », ni ouvertement militante, comme celle des guides de Géorgie et de Virginie, qui récusent l'idée de folklore noir et signalent l'avènement de cultures - et de "races »-nouvelles et métissées. Si cette stratégie caractérise la plupart des guides du Sud, elle était loin d'être la seule, et ne correspondait pas à celle du directeur fédéral des "études noires", le poète noir Sterling Brown, dont l'essai sur les Noirs dans le guide de Washington constitue la plus virulente critique de la collection. Les représentations du folklore noir dans les guides dépendit donc plutôt de la composition et de la perspective des équipes locales.

Dans les guides des états industriels du Nord, le recours à la notion de «folklore vivant » relevait de la nécessité pragmatique. Pauvres en culture paysanne, ces états pouvaient s'enorgueillir d'une riche tradition ouvrière, souvent promue "culture folklorique » en lieu et place du folklore traditionnel. La où le «folklore " servit souvent à exclure les Noirs de la communauté politique dans les états du Sud, le folklore ouvrier (industrial lore) servit à l'inverse à introduire dans la littérature touristique une population et une culture politique qui en étaient traditionnellement absentes. La « tradition syndicale » permettait en effet aux auteurs de décrire en détails les gestes politiques promus " pratiques culturelles » de ce «folk» d'un genre nouveau. Les guides du Michigan, du Wisconsin et de l'Ohio décrivent par exemple en détails les formes historiques de résistance ouvrière. De la destruction des machines à l'occupation des usines en passant par la grève, ces guides livrent un précis d'histoire ouvrière qui réinscrit ces pratiques dans une longue tradition, inventant au passage un véritable "folklore ouvrier» digne du «folklore paysan » des guides Baedekers. Le monde paysan, loin d'être idéalisé, n'y figure souvent qu'en termes de misère et d'analphabétisme.

Tous les guides ne sacrifient pas aussi volontiers le «folklore traditionnel » à l'autel de ce «nouveau folklore». Le guide de Virginie occidentale tente de tous les rassembler sous la même bannière « locale ». Fermiers des plaines - qui « ne savent pas pourquoi ils ne veulent pas se mélanger, il n'en ont juste pas envie»-hillbillies des montagnes - « méfiants à l'égard du confort moderne, préférant aller pieds nus en été et rejetant les principes d'éducation moderne»-ouvriers des nouvelles industries - « aux cheveux lissés, élégants, lisant les journaux et s'engageant »-et mineurs du sud - qui «se mettent courageusement en grève pour ce qu'ils estiment être socialement, économiquement et politiquement juste »-forment une improbable coalition d' "hommes du commun » et de "types locaux », auxquels sont opposés les 
"types de nulle part ", «qu'on trouve partout »- petits commerçants "qui ne savent pas de quel côté ils sont, celui des employés ou des employeurs » - riches Virginiens et rédacteurs de journaux locaux «soit disant indépendants». Le «folk» de Virginie occidentale assimile ses ouvriers et ses paysans comme le personnage légendaire de John Henry - «incontestablement le personnage folklorique le plus important de l'état»-rassemble à lui tout seul toutes les facettes du nouveau folk: à la fois personnage de légendes folkloriques "traditionnelles", mineur de l'industrie et noir, John Henry possède en effet toutes les qualités requises pour figurer en bonne place au panthéon folklorique du New Deal.

Le guide de l'état de Floride est un des rares guides du Sud qui déploie une stratégie similaire de récupération positive de la civilisation industrielle et de rassemblement ou réconciliation de tous les prétendants au «folk» en une seule entité «locale». Le chapitre introductif, intitulé "scène contemporaine ", s'ouvre sur un tableau ironique où toutes les communautés folkloriques d'antan-pionniers, Indiens Séminoles, fermiers - se sont transformées en exploitations touristiques. Les pionniers comme les Indiens posent en costumes traditionnels le long du Tamiami trail-ces Indiens Séminoles que même l'armée américaine n'avait pas réussi à déloger des Everglades se sont «rendus à la puissance touristique». Les paysans ont troqué depuis bien longtemps l'élevage de vaches contre celui d'alligators, plus exotiques et prisés des visiteurs. Les chanteurs de country music ont déserté leur campagne pour venir jouer des mélodies venues du Bronx aux touristes new-yorkais qui n'y voient que du feu. Ce tableau post-moderne de la Floride en gigantesque parc d'attractions touristiques ne se conclut pourtant pas, comme le lecteur s'y attend: loin de se lamenter sur la disparition de toute authenticité ou d'évoquer nostalgiquement la Floride d'antan le récit se termine par le rejet de cette nostalgie facile. La Floride d'antan, rappelle-t-il, n'était qu'un marais infectieux que seuls les efforts sans relâche des citoyens devenus exploitants touristiques sont miraculeusement parvenus à assainir. "Si ces efforts venaient à être relâchés", prévient le narrateur, "une bonne partie de la Floride redeviendrait sauvage. En combattant la nature et en tentant de réconcilier des idées divergentes, le citoyen fait acte de civisme et si le climat, comme le prétendent les publicité, prolonge de dix ans son espérance de vie, ce sursis est mis au service et au bénéfice de l'état ». Le récit se termine par une réfutation cinglante de «la théorie en voie de disparition" selon laquelle "la Floride doit appartenir aux Floridiens et ne devrait pas être exploitée pour le compte de visiteurs étrangers ». La boucle est bouclée : dans la Floride du guide du FWP, ce ne sont plus les folklores et les cultures ancestrales qui sont en voie de disparition mais bien plutôt l'idée saugrenue qu'il conviendrait de lutter contre cette disparition. L'industrie touristique dans le guide de Floride représente à la fois le seul salut économique de l'état (chapitre histoire) et désormais aussi sa seule « culture locale ».

Les analyses historiographiques contrastées des guides du FWP témoignent à la fois de la diversité du corpus - qui décourage la généralisation-et de l'époque historiographique dans laquelle s'inscrivaient les historiens eux-mêmes. Là où les historiens des années 1970 restaient dans la lignée de l'entreprise new dealienne, l'historiographie contemporaine se fonde à l'inverse sur une distance critique vis à vis des prétentions « universalistes » du New Deal. Les guides du FWP aspiraient en effet peut-être plus encore que d'autres à une forme d'universalisme objectif. Il s'agissait en grande partie d'accomplir pour la littérature ce que les documentaristes de la FSA voulaient accomplir dans le domaine de la photographie : faire de l'auteur un simple 
"opérateur» (et non un véritable photographe) dont les "vues» (au sens photographique du terme) témoignaient de la réalité, documentaient le réel, plus qu'elles ne l'interprétaient. Le style des guides visait en effet à incarner cette sorte de « degré zéro de l'écriture » et signaler l'abolition du style comme de l'auteur et de sa perspective.

La mainmise de la direction sur la production des guides et le caractère construit de cette " perspective absente » méritent d'être soulignés. Mais les guides du FWP ne se situent pas pour autant dans la lignée des Baedekers et autres collections européennes dont ils semblaient pourtant en partie s'inspirer. Ils forment bien plutôt une sorte d'entre deux - entre multiculturalisme revendiqué et réflexe réactionnaire-et incarnent en eux-mêmes, par la diversité des angles qu'ils adoptent et juxtaposent au sein d'une même collection, l'échec de la narration, l'impossibilité du consensus. Le folklore en particulier constitue le terrain privilégié de l'affrontement entre les plus militants des deux bords et cette "voie médiane» et consensuelle. Il constitue également le terrain où s'exprime le plus directement la "perspective» des équipes locales, qui à défaut d'être "populaire ", échappait à tout le moins à l'emprise de la direction fédérale.

\section{BIBLIOGRAPHIE}

The American Guide Manual, octobre 1935, National Archives ( ci-après NARA) (RG9 PI57).

Supplementary Instructions 9, on Folklore, 12 mars 1936, NARA (RG 69 PI57).

BEARD, Charles and Mary, The Rise of American Civilization, New York, Macmillan Company, 1930.

BOLD, Christine, The WPA Guides : Mapping America, Jackson, MS, University Press of Mississippi, 1999.

BOTKIN, Benjamin Albert, « We Called It Living Lore », New York Folklore Quarterly, vol. 14, n³, Fall 1958.

BRUNET, François, La naissance de l'idée de photographie, Collection Sciences, modernités, philosophies, Paris, Presses universitaires de France, 2000.

Federal Writers' Project, Florida; a Guide to the Southernmost State, American Guide Series, New York, Oxford University Press, 1939, xxvi, 600 p.

---, Georgia : a Guide to its Towns and Countryside, American Guide Series, Athens, University of Georgia Press, 1940, xxviii, 559 p.

-- , Kentucky; a Guide to the Bluegrass State, American Guide Series, New York, Harcourt, 1939, xxix, $489 \mathrm{p}$.

---, Michigan; a Guide to the Wolverine State, American Guide Series, New York, Oxford University Press, 1941, xxxvi, $682 \mathrm{p}$.

--_, Mississippi; a Guide to the Magnolia State, American Guide Series, New York, The Viking Press, $1938,545 \mathrm{p}$. 
--_, North Carolina, a Guide to the Old North State, American Guide Series, Chapel Hill, The University of North Carolina Press, 1939, xxxiv, 601 p.

-_-, The Ohio Guide, American Guide Series, New York, Oxford University Press, 1940, xxxi, 634

p.

-_-, South Carolina; a Guide to the Palmetto State, American Guide Series, New York, Oxford University Press, 1941, xxvii, 514 p.

---, Virginia, a Guide to the Old Dominion, American Guide Series, New York, Oxford University Press, 1940, xxix, $699 \mathrm{p}$.

---, Washington, City and Capital, American Guide Series, Washington, D.C., U.S. Govt. Print. Off., 1937, xxvi, 1140p.

---, West Virginia; a Guide to the Mountain State, American Guide Series, New York, Oxford University Press, 1941, xxxi, 559 p.

---, Wisconsin; a Guide to the Badger State, New York, Duell, 1941, 651p.

HURSTON, Zora Neale, Go Gator and Muddy the Water : Writings, 1st edition, New York, Norton, 1999, xvi.

KAMMEN, Michael G., Mystic Chords of Memory : the Transformation of Tradition in American Culture, 1st, New York, Knopf, 1991, 864 p.

KELLOCK, Katherine, « The WPA Writers : Portraitists of the United States », American Scholar, Autumn 1940, p. 473-482.

LOMAX, John Avery, Adventures of a Ballad Hunter, 1st printing., New York, Macmillan, 1947, xi, $302 \mathrm{p}$.

MANGIONE, Jerre Gerlando, The Dream and the Deal : the Federal Writers' Project, 1935-1943, New York, Avon Books, 1972, xiv, 418 p.

McDONALD, William Francis, Federal Relief Administration and the Arts; the Origins and Administrative History of the Arts Projects of the Works Progress Administration, Columbus, Ohio State University Press, 1969, xiv, 869 p.

PENKOWER, Monty Noam, The Federal Writers' Project ; a Study in Government Patronage of the Arts, Urbana, University of Illinois Press, 1977, xii, 266 p.

PORTERFIELD, Nolan, Last Cavalier : the Life and Times of John A. Lomax, 1867-1948, Folklore and society, Urbana, University of Illinois Press, 1996, 580 p.

SUSMAN, Warren, Culture as History : the Transformation of American Society in the Twentieth century, 1st, New York, Pantheon Books, 1984, xxx, 321 p.

THIESSE, Anne-Marie, La création des identités nationales : Europe, XVIIIe-XXe siècle, L'univers historique, Paris, Seuil, 1999, 302 p.

INDEX

Keywords : New Deal, folklore, guide-books, Federal Writers' Project, folklore

Mots-clés : guides touristiques, programme pour les écrivains 
AUTEUR

NINON VINSONNEAU

Université Paris VII 